Portland State University

PDXScholar

$5-24-2019$

\title{
Exploring Small Business Management in Mexico and the United States using Hofstede's Dimensions
}

\author{
Elizabeth R. Thom \\ Portland State University
}

Follow this and additional works at: https://pdxscholar.library.pdx.edu/honorstheses

Let us know how access to this document benefits you.

\section{Recommended Citation}

Thom, Elizabeth R., "Exploring Small Business Management in Mexico and the United States using Hofstede's Dimensions" (2019). University Honors Theses. Paper 719.

https://doi.org/10.15760/honors.736

This Thesis is brought to you for free and open access. It has been accepted for inclusion in University Honors Theses by an authorized administrator of PDXScholar. Please contact us if we can make this document more accessible: pdxscholar@pdx.edu. 


\title{
Exploring Small Business Management in Mexico and the United States using Hofstede's Dimensions
}

\author{
By \\ Elizabeth Thom \\ An undergraduate honors thesis submitted in partial \\ fulfillment of the requirements for the degree of \\ Bachelor of Arts \\ In \\ University Honors \\ And \\ Human Resource Management \\ (School of Business Administration)
}

Thesis Advisor

Lihong Qian, PhD

Portland State University 
Table of Contents

Research Question $\quad 3$

$\begin{array}{ll}\text { Abstract } & 3\end{array}$

Spring 2019 BA 495 Client 5

$\begin{array}{lr}\text { Four Hofstede Dimensions } & 6\end{array}$

The United States vs. Mexico on Hofstede's Dimensions 9

Significance of the Dimensions in Scholarly Work 11

Research Gaps and Limitations 12

Hofstede's Implications for the Workplace 15

Power Distance $\quad 16$

Uncertainty Avoidance $\quad 18$

Individualism $\quad 19$

Masculinity 20

Customer Perspective $\quad 23$

Compensation and Benefits Practices $\quad 23$

$\begin{array}{ll}\text { Case Study } & 24\end{array}$

Thesis Paper Limitations and Directions for Future Research 25

Recommendations 26

$\begin{array}{lr}\text { References } & 30\end{array}$ 


\section{Research Question}

Using Hofstede's Dimensions, how can small businesses structure organizations to maximize organizational effectiveness and employee satisfaction? To what extent will the administration of small businesses differ depending on the cultural space the organization is operating in and what best practices must business leaders be mindful of depending on varying societal values?

\section{Abstract}

This thesis paper will consider cultural differences that lead to different processes to achieve workplace effectiveness using the Cultural Dimensions outlined by notable scholar, Geert Hofstede and use said findings to provide theoretical and general recommendations for my Capstone client. The literature review will highlight important themes that tend to occur in organizations of specific dimensions. In consideration of these themes, I will highlight the best business practices for small businesses. For comparison purposes, I will specifically focus on the United States and Mexico, where Company X has expressed interest in ultimately opening a high-end retail storefront, using research surrounding Hofstede's Cultural Dimensions. This literature review defines and refers to culture as Hofstede did, the collective programming of the mind that distinguishes one group from another (Hofstede, 2011).

I will begin by outlining the cultural dimensions of focus, then move on to explain their relevance. I will include specific case studies in which organizational culture was analyzed and consider best practices to theoretically advise the client to consider once the business is more 
developed. This research question is relevant for business administration, and specifically human resources management for a multitude of reasons. Schuler \& Rogovsky concluded that national culture is a significant explanatory factor for cross-country differences in HR practices and policies and that matching human resources functions to country-specific culture is important because it conveys cultural awareness and sensitivity, communicates expectations of employee behavior consistent with ingrained patterns of acceptable behavior, and results in higher levels of company financial performance, (1998). However, research finds that firms do not understand the importance of developing a national culture-specific work environment and this may explain the inefficiencies in management by factors related to cross-cultural mismanagement, (Punnet \& Ricks 1992). While it appears that many organizations underestimate the value of cultural sensitivity in the workplace, Newman and Nollen (1996) concluded that organizations with culturally consistent practices had better financial performance outcomes than firms with culturally inconsistent practices.

My inspiration for this paper aroused when an HR professional told me of a story, a common narrative, about her accidental negative work interaction while she was abroad in Japan in which she unintentionally offended a potential business partner. This HR professional flew to Asia to represent her multinational United States-based company, hoping to land a great deal on behalf of her organization. She soon met with some of the most high-ranking people in this Japanese company. Upon receiving a business card from an influential Japanese executive, she promptly placed the business card in her wallet. To her dismay, she was later told that this act was highly unprofessional and seen as rude. It proved to be the case that in Japan, putting a business card away indicates that the individual is not worth your time. In the United States, an 
act such as placing a business card in a wallet would be viewed as respectful, because you are storing the card for safekeeping. This HR professional did not anticipate this specific cultural subtlety that led to her accidental offense. While impossible to memorize every single nuance in every unique society, recognizing cultural trends and attitudes enables us to communicate better, do business effectively, and empathetically relate to others.

\section{Spring 2019 BA 495 Client}

For this paper, I will conceal the name of the client. The client shall be referred to as Company X or simply "the client" for the duration of this paper to ensure anonymity. Company $\mathrm{X}$ is a small fashion company operating in Portland, OR with no employees besides the owner-operator. Company X creates handmade, high-end product for women from sustainable, quality textiles. One local boutique in the Portland metro area features Company X merchandise. Company $\mathrm{X}$ does not have a retail space of its own, nor does it possess the funds or business development to do so at this time practically. Once fundamental business operations are mastered such as adequate supply chain that meets business needs, basic and proper revenue and accounting, obtainment of a loyal customer base, and effective marketing campaigns, the client hopes to open a retail space of its own featuring entirely Company X product. The owner and operator moved from Mexico to Portland, OR and has expressed interest in opening this future retail space in either Mexico or the United States. However, the possibility of a Company X storefront is significantly down the line as online sales are non-existent, despite the investment into a website capable of processing online orders. More practical, and immediately necessary business consulting has taken place in BA 495. However, the recommendations in this paper will 
center around how best business practices adjust given the location of a future, hypothetical storefront.

\section{Four Hofstede Dimensions}

One of the most widely cited metrics of culture is from Hofstede outlining his theorized Cultural Dimensions. Hofstede outlines simple dimensions that, together, thoroughly describe the most fundamental attributes of cultures all around the world. The six dimensions include Individualism, Uncertainty Avoidance, Power Distance, Masculinity, Long Term Orientation, and Indulgence. However, peer-reviewed research has identified the dimensions Individualism, Uncertainty Avoidance, Power Distance, and Masculinity as the most relevant Hofstede dimensions that pertain to work; therefore only those four dimensions will be covered in this literature review.

The dimension of national culture, Power Distance Index, is the degree to which less powerful members of a society accept inequalities among people and expect that power reflects rigid hierarchical order in which those in power have a place and do not need a justification to earn compliance. In colloquial terms, Power Distance describes responses to inequality. Low Power distance societies tend to minimize status differences among people and "level the playing field," so to say. Uncertainty Avoidance is characterized by how comfortable individuals feel with uncertainty and ambiguity. This is the level of stress brought on by unknown future. While some cultures embrace uncertain futures, others prioritize stiff codes of belief and behavior and are generally intolerant of unorthodox change within society. Low Uncertainty Avoidance countries tend to view high Uncertainty Avoidance countries as traditional and stiff. 
Individualism vs. Collectivism is the notion of where people define themselves, whether that be within their own self or upon group community and mainly refers to people's integration into primary groups. Collectivism represents a tight-knit framework in which relatives and members of the specific group give unwavering loyalty to one another. The Masculinity dimension represents a society's orientation towards materialism and achievement. The opposite, femininity, represents values such as quality of life. Femininity oriented communities handle matters in more consensus-oriented fashions.

Table 1 - Power Distance Characterizations (Hofstede, 2011)

\begin{tabular}{|c|c|}
\hline Small Power Distance & Large Power Distance \\
\hline $\begin{array}{l}\text { Use of power should be legitimate and is } \\
\text { subject to criteria of good and evil }\end{array}$ & $\begin{array}{l}\text { Power is a basic fact of society antedating good or } \\
\text { evil: its legitimacy is irrelevant }\end{array}$ \\
\hline Parents treat children as equals & Parents teach children obedience \\
\hline Older people are neither respected nor feared & Older people are both respected and feared \\
\hline Student-centered education & Teacher-centered education \\
\hline $\begin{array}{l}\text { Hierarchy means inequality of roles, } \\
\text { established for convenience }\end{array}$ & Hierarchy means existential inequality \\
\hline Subordinates expect to be consulted & Subordinates expect to be told what to do \\
\hline $\begin{array}{l}\text { Pluralist governments based on majority vote } \\
\text { and changed peacefully }\end{array}$ & $\begin{array}{l}\text { Autocratic governments based on co-optation and } \\
\text { changed by revolution }\end{array}$ \\
\hline Corruption rare; scandals end political careers & Corruption frequent; scandals are covered up \\
\hline Income distribution in society rather even & Income distribution in society very uneven \\
\hline Religions stressing equality of believers & Religions with a hierarchy of priests \\
\hline
\end{tabular}

Table 2 - Uncertainty Avoidance (Hofstede, 2011) 


\begin{tabular}{|c|c|}
\hline Weak Uncertainty Avoidance & Strong Uncertainty Avoidance \\
\hline $\begin{array}{l}\text { The uncertainty inherent in life is accepted and } \\
\text { each day is taken as it comes }\end{array}$ & $\begin{array}{l}\text { The uncertainty inherent in life is felt as a } \\
\text { continuous threat that must be fought }\end{array}$ \\
\hline Ease, lower stress, self-control, low anxiety & Higher stress, emotionality, anxiety, neuroticism \\
\hline $\begin{array}{l}\text { Higher scores on subjective health and well- } \\
\text { being }\end{array}$ & Lower scores on subjective health and well-being \\
\hline $\begin{array}{l}\text { Tolerance of deviant persons and ideas: what is } \\
\text { different is curious }\end{array}$ & $\begin{array}{l}\text { Intolerance of deviant persons and ideas: what is } \\
\text { different is dangerous }\end{array}$ \\
\hline Comfortable with ambiguity and chaos & Need for clarity and structure \\
\hline Teachers may say 'I don't know' & Teachers supposed to have all the answers \\
\hline Changing jobs no problem & Staying in jobs even if disliked \\
\hline Dislike of rules - written or unwritten & Emotional need for rules - even if not obeyed \\
\hline $\begin{array}{l}\text { In politics, citizens feel and are seen as } \\
\text { competent towards authorities }\end{array}$ & $\begin{array}{l}\text { In politics, citizens feel and are seen as } \\
\text { incompetent towards authorities }\end{array}$ \\
\hline $\begin{array}{l}\text { In religion, philosophy and science: relativism } \\
\text { and empiricism }\end{array}$ & $\begin{array}{l}\text { In religion, philosophy and science: belief in } \\
\text { ultimate truths and grand theories }\end{array}$ \\
\hline
\end{tabular}

Table 3 - Individualism Characteristics (Hofstede, 2011)

\begin{tabular}{|c|c|}
\hline Individualism & Collectivism \\
\hline $\begin{array}{l}\text { Everyone is supposed to take care of him- or } \\
\text { herself and his or her immediate family only }\end{array}$ & $\begin{array}{l}\text { People are born into extended families or clans } \\
\text { which protect them in exchange for loyalty }\end{array}$ \\
\hline "I" - consciousness & "We" -consciousness \\
\hline Right of privacy & Stress on belonging \\
\hline Speaking one's mind is healthy & Harmony should always be maintained \\
\hline Others classified as individuals & Others classified as in-group or out-group \\
\hline Personal opinion expected: one person one vote & Opinions and votes predetermined by in-group \\
\hline Transgression of norms leads to guilt feelings & Transgression of norms leads to shame feelings \\
\hline Languages in which the word "l" is indispensable & Languages in which the word "I" is avoided \\
\hline Purpose of education is learning how to learn & Purpose of education is learning how to do \\
\hline Task prevails over relationship & Relationship prevails over task \\
\hline
\end{tabular}

Table 4 - Femininity and Masculinity Characteristics (Hofstede, 2011) 


\begin{tabular}{|c|c|}
\hline Femininity & Masculinity \\
\hline $\begin{array}{l}\text { Minimum emotional and social role differentiation } \\
\text { between the genders }\end{array}$ & $\begin{array}{l}\text { Maximum emotional and social role differentiation } \\
\text { between the genders }\end{array}$ \\
\hline Men and women should be modest and caring & $\begin{array}{l}\text { Men should be and women may be assertive and } \\
\text { ambitious }\end{array}$ \\
\hline Balance between family and work & Work prevails over family \\
\hline Sympathy for the weak & Admiration for the strong \\
\hline $\begin{array}{l}\text { Both fathers and mothers deal with facts and } \\
\text { feelings }\end{array}$ & Fathers deal with facts, mothers with feelings \\
\hline $\begin{array}{l}\text { Both boys and girls may cry but neither should } \\
\text { fight }\end{array}$ & $\begin{array}{l}\text { Girls cry, boys don't; boys should fight back, girls } \\
\text { shouldn't fight }\end{array}$ \\
\hline Mothers decide on number of children & Fathers decide on family size \\
\hline Many women in elected political positions & Few women in elected political positions \\
\hline Religion focuses on fellow human beings & Religion focuses on God or gods \\
\hline $\begin{array}{l}\text { Matter-of-fact attitudes about sexuality; sex is a } \\
\text { way of relating }\end{array}$ & $\begin{array}{l}\text { Moralistic attitudes about sexuality; sex is a way } \\
\text { of performing }\end{array}$ \\
\hline
\end{tabular}

\section{The United States vs. Mexico on Hofstede's Dimensions}

Each country in Hofstede's Cultural Dimensions index is positioned on a score from 1-100 for comparison value. See Table 5 for results on the countries of focus, the United States, and Mexico. On the four dimensions in this literature review, Mexico and the United States rank essentially opposite in each metric except for Masculinity and Femininity, in which the scores are very similar. This indicates that culturally, the two countries differ appreciably.

The countries rank significantly different in terms of Power Distance. A high Power Distance score indicates substantial importance of hierarchy and implicit respect for authority figures. Mexico is a high Power Distance country scoring 81 on Hofstede's Scale. Mexico being a hierarchical society, indicates that authority figures need not justify their authority. Meanwhile, the United States is much less rigid in this regard, scoring only 40. In the United States, hierarchy is constructed more for convenience purposes because people expect consultation regardless of personal power. It is theorized that this tendency can be attributed to the American 
promise of "liberty and justice for all" in which there is an explicit emphasis on equality in society and government from the early establishment of the country, (Hofstede Insights, n.d.).

Each country's degree of individualism draws the most striking comparison. The United States is one of the most individualistic countries in the world and stands at a score of 30 . Mexico, on a scale of $1-100$, is exceptionally high at a 91 . The United States has a fundamental expectation that people look after themselves and perhaps their immediate family. Otherwise, groups tend to be loosely knit with little reliance on authorities for support. Contrarily, Mexicans tend to place the highest value in society on loyalty and long-term commitment, which rises above other societal expectations. Bad behavior of one member can lead to feelings of shame for the entire group, (Hofstede Insights, n.d.). Strong relationships and organizational ties carry significant weight in Mexico compared to the United States.

Masculinity levels are similar in these two countries, with Mexico scoring 69 and the United States scoring 62. Both societies are more driven by competition, achievement, and success, with a strong urge to "win," so to say. Neither country is as influenced by the feminine values of quality of life and caring for others. However, though these levels are similar, these drives can manifest themselves differently based on the society's uncertainty avoidance metric. Societies low in Uncertainty Avoidance generally demonstrate this drive up front, by boasting about achievements and materialistic attainments. The accomplishment in and of itself is not the primary motivator in the United States. Instead, it is prosperity on display. That may manifest itself as a new car, fancy neighborhood, or nice clothes. In Mexico, this drive is more subtle on the outside. 
Mexico and the United States differ in their respective tolerance for uncertainty avoidance in which those in the United States tend to embrace ambiguity, and those in Mexico avoid uncertain situations with rigid rules and sets of beliefs. Cultures high in uncertainty avoidance tend to resist change and find security in staying busy and even resisting innovation. Mexico ranks high on the scale, 82 , while the United States is below average at 46 . Americans are generally more tolerant of new ideas and willing to try new things with much more acceptance. However, Hofstede's Insights notes that since terrorist attacks in 2001, Americans have grown more wary and fearful.

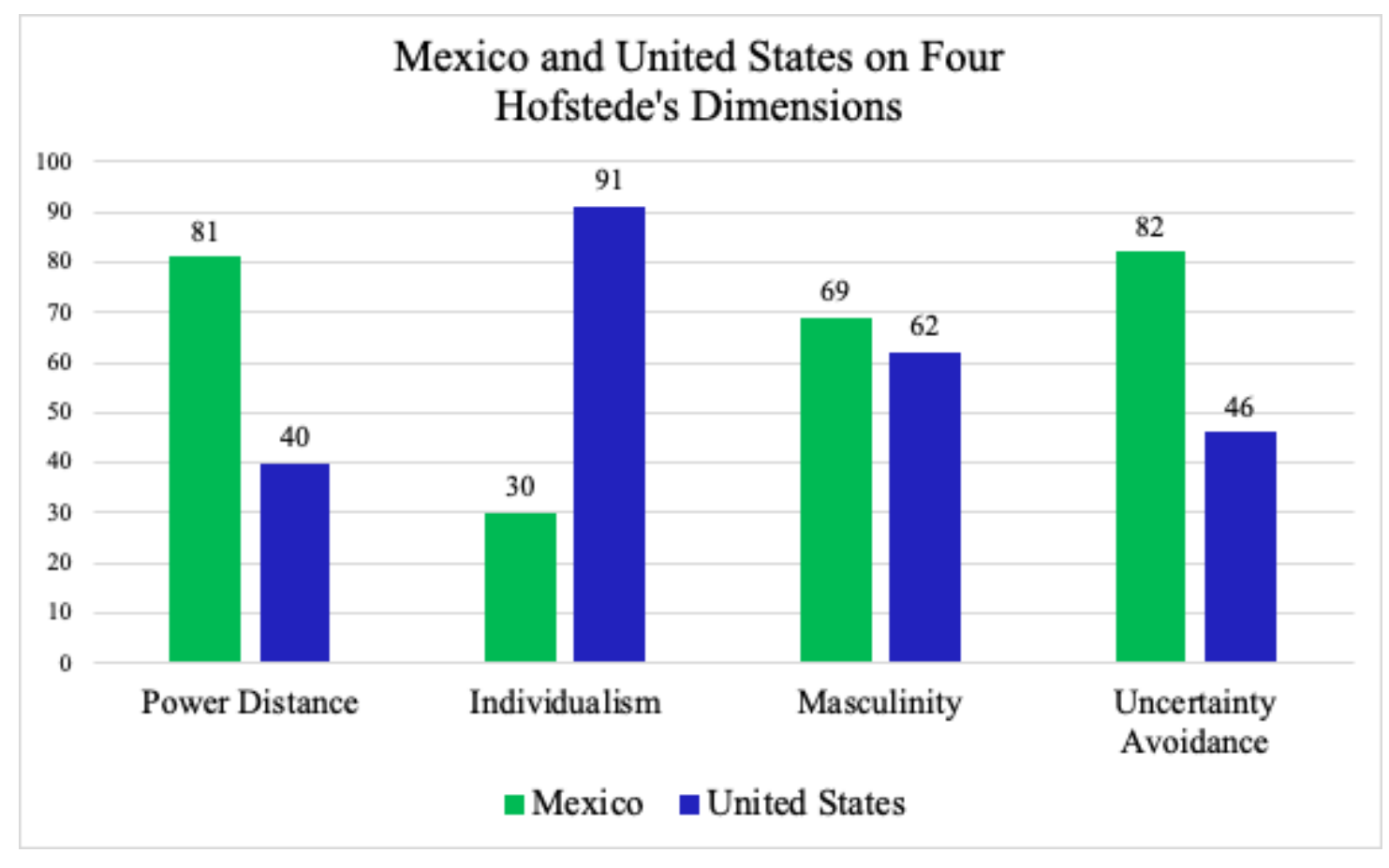

\section{Significance of the Dimensions in Scholarly Work}

Government practice, expected standard practice, and employee expectations all play a significant role in creating business organizational effectiveness (Hempel, 1998). While 
understanding differences among cultures is certainly not the end all be all for reducing adverse work outcomes, it helps leaders empathize with employees more easily and manage effectively. Organizations in different countries are often faced with similar problems but address those same workplace issues with different solutions, (Hofstede 2001). When all other factors are equal, organizational structures and management processes vary among countries. Hofstede is hugely influential in the scholarship community of considering the significance and disparities between countries. Hofstede's 1980[2001] publications, “Culture's consequences: International differences in work-related values" is cited almost 80,000 times alone. It is among the top 25 most cited books in all social sciences, (Green 2016).

\section{Research Gaps and Limitations}

There is currently a research gap between the relationship of individualism in a society and organization in correlation with turnover trends. When managing a business, leaders aim to avoid turnover to lower costs and maximize operational excellence. Training, hiring, and recruiting are one of the most expensive functions of a business. Turnover is one of the most researched and studied topics in the organizational sciences field. However, little research exists on national culture as it relates to employee turnover (Maertz, 2004). Turnover and cultural differences are an exciting dynamic to study because there is the question of whether or not people in a collectivist society, such as Mexico, leave jobs for the same reasons that people in individualist societies, such as the United States, exit. Knowing this relationship will help business owners and leaders prevent turnover in their organizations. Most studies predict that job fit assumes greater importance in individualistic societies while organization fit and organization 
links will imply more influence in collectivistic cultures. Person-job fit is a higher predictor of retention in individualistic countries, whereas in collectivist countries, person-organization fit needs to be of higher importance. In a research study on call centers, researchers found that community links in India were more critical than in the United States, (Ramesh and Gelgand, 2010). As a result, the organization links increased, the probability of job abandonment decreased. Organizational outcomes often connect to community links. When cultures drive on community interconnectedness, there are a few ways managers can integrate those values into daily work life. Organizational practices targeted at increasing associational links, such as creating teams or groups in which individuals depend on one another, recruiting and on-boarding new employees in groups, or creating a mentor or buddy system for employee socialization, can lead to higher retention in a collectivistic culture, (Ramesh \& Gelfand, 2010).

Most individualist cultures value autonomy, competition, and independence. These internal attributes encourage a person to fulfill their own potential. Therefore, a workplace that drives those motivations may do better in a country such as the United States rather than Mexico. Although many authors have suggested that the importance of person-job fit for turnover might not be as high in other cultures as it is in the United States (Sekiguchi, 2004; Sinha \& Sinha, 1990).

A primary research limitation is a variance between how small business enterprises (henceforth known as SMEs) are referenced in literature and the availability of research connecting small businesses to cultural orientations in business management. Generally, the discourse surrounding this topic focuses on large enterprises. Regardless, the U.S. Small Business Administration usually categorizes "small enterprises" as organizations employing less 
than 100 employees and medium organizations employing less than 500 employees, though these numbers may change depending on the industry. There is no clear consensus on the definition of SME, and the term's usage can vary depending on region and prevailing social conditions, (Rijirawanich, Addison \& Smallman 2001). At this time, Company X does not have any employees besides the owner and is undoubtedly considered a "small business." Theoretical recommendations in this paper can stand given the assumption of future business growth; however, the employee count necessary remains unknown and heavily under assumption. This inconsistent definition is relevant to note because business operations can significantly vary between 10 employees versus 400 employees.

It is important to note the limitations of Hofstede's Dimensions before heavily depending on them to make business decisions. Though Hofstede's dimensions are often viewed as the most accepted and comprehensive framework for recognizing cultural inclinations for specific countries, his theoretical framework receives criticism for the following reasons. First, the primary limitation of Hofstede's dimensions is the high degree of generalization in describing complex societal norms. While these dimensions tend to quite accurately to reflect overall populations, specific individuals often belong to sub-cultures that may fit a different mold than outlined by Hofstede. Hofstede himself has acknowledged this criticism responding that generalizations are useful as practical tools provided that they are treated as such, especially given that culture in and of itself is a theoretical construction. In a 1993 interview with Richard Hodgetts, Hofstede said "We are dealing with a "construct" here-that is, a tool for analysis. Some of the younger students and researchers, in my view, tend to look at the dimensions as concrete entities. However, the sole purpose of the dimensions is to add some structure to concepts that 
would otherwise be too complex to easily contrast and grasp. There are also questions regarding the accuracy of the data. Data is collected through questionnaires, and unintentional survey implicit bias theories suggest that people responding to surveys regarding culture may unintentionally respond through the stereotypical lens of someone living in that country. This inherent bias may exaggerate results more so than appropriate. Last, some critics refer to the original data by Hofstede being almost 50 years old. However, subsequent data collected on year by year basis has since been consistent with initial findings.

The criticism that these dimensions tend to overly simply huge demographics of people is especially pertinent in the case of using them to make small business organizational decisions. While large corporations may need to heavily research and study societal trends and attitudes as a whole, small businesses, Company $\mathrm{X}$ in particular, are very geared toward the individual consumer and therefore should be advised to conduct more specific subculture market research in the region in which the company is operating in rather than only consider Cultural Dimensions. To refine these generalizations to provide recommendations for this paper, I will discuss distinct case studies.

\section{Hofstede's Implications for the Workplace}

These dimensions have inherent implications for work in that culture begins with the household, presumably as a child growing up, and particular dynamics transfer into the workplace upon growing into adulthood. For example, people go through learning experiences as children in the home and as students at school. Certain dynamics that young people become used to such as teacher-student and parent-child naturally transfer when the time comes for more 
formal supervisor-subordinate relationships. This is how our mental programming in society from the time that we are very small develops into professional tendencies.

The implications outlined are often similar for small businesses as they are large companies and affect organizations of all sizes in similar ways. However, business of scale can affect the feasibility of specific changes. Small businesses, though lacking in resources, usually are more flexible and able to be ever-changing. Roles are often less straightforward and narrow; thus employees of small firms are ready to be more dynamic. In addition, employees in small businesses can more easily make their opinions heard, rather than get lost in the bureaucratic red tape characterized by corporations. Often, these implications can lead to changes that would not necessarily add exorbitant costs for small businesses but instead establish reprioritization. Tessema and Embaye found that regardless of country's culture, such as individualistic vs collectivistic, and level of economic development, employees need to be recognized and praised for the value that they add to the organization in order to keep morale high, (2013). Employee recognition is easily implemented at all levels of business, from small to large.

\section{Power Distance}

Workplace cultures in organizations with high power distance levels, such as Mexico, are generally characterized by hierarchical systems with an understanding of existential inequality. Organizations typically centralize power and staff a significant amount of supervisory personnel so that subordinates regularly receive clear direction. Compensation is usually salaried with wide gaps for top and bottom roles in the tall hierarchies. Here, people expect inequalities to some extent, and some would say they are actually desired. Contrarily, small distance societies 
generally view a difference in job positions as unequal in authority for convenience, but more existentially equal. Organizations typically have a much flatter organizational structure with less "bosses." Salary differences are also generally more minimal. Superiors are expected to be available for subordinates and "in the trenches" with them, so to say, (Hofstede, 1997).

High Power Distance has enormous implications for employee-supervisor relationships in the workplace and can lead to fear of disagreement when all authority is held in the hands of a single superior. Conflict fear is one of the number one methods of exploring power distance measures, (Hofstede 2001). "People learn to behave submissively - at least in the presence of the boss. They do not learn to thrash things out with him, face-to-face. Then when there is no reason to fear, they still do not feel that it is natural to speak up," (Whyte 1969). Fear of argument is an issue in the workplace because it discourages collaboration and effective problem-solving. A study on leadership methods surveyed (Pavett and Morris 1995) 180 managers in multiple multinational corporations in five countries: Great Britain, Italy, Mexico, Spain, and the United States. The study used Likert's (1976) Profile of Organizational Characteristics of classifying management style from exploitative authoritative, benevolent authoritative, consultive, and participative. Ratings of each management style varied by country. Mexico averaged a score of 7.9, which indicates a typical management style being "benevolent authoritative" while the United States averaged a "consultative" management style. This study's findings are directly in line with characterizations made by Hofstede's Cultural Dimensions. The Power Distance Index also has implications for preferred managers. Subordinates in high-PD countries prefer managers who make decisions promptly and independently but provide the rationale for decisions made whereas subordinates in low-PD countries express a preference for managers that consult 
employes prior to making decisions and considers the advice given before making a decision, (Hofstede 2001). These studies support the understanding that low-PDI societies thrive on consultative leadership where the ideal boss is viewed as resourceful and democratic. Organizations in low-PDI societies tend to do better with flatter organization pyramids and decentralized decision structures. Whereas high-PDI societies gain the same result of satisfaction, performance, and productivity through more authoritative leadership and supervisory personnel with the ideal boss seen as a well-meaning autocrat and benevolent decision maker in which subordinates are told rather than consulted, (Hofstede 1980).

\section{Uncertainty Avoidance}

The degree of uncertainty avoidance is highly visible in an organization by the formal rules controlling rights and duties of employees. Here, uncertainty avoidance ties with power distance in which high power distance societies coupled with high uncertainty avoidance countries result in employees with very little discretionary power, (Hofstede 2001). This need for strict rules is hypothesized by Hofstede to stem from early childhood in which kids are raised to thrive in highly structured environments. However, this emotional need for rules may result in actually dysfunctional policies put forth to provide regulation but decrease productivity. Countries high in uncertainty avoidance tend to have complex corporate structures while lower levels of uncertainty avoidance have looser organizational structures for quicker decision-making, (Samuel, Clayton, \& Hannah, 2016). Studies reveal that individuals in high uncertainty avoidance societies, such as Mexico with a high score of 82, are slower to recognize 
ineffective rules and are thus less likely to repeal work-hindering regulations, potentially disadvantaging organizations operationally.

A society's Uncertainty Avoidance Index will implicate work primarily in terms of employment stability and seniority. A 1997 report from the Organization for Economic Cooperation and Development found a strong correlation between the average duration of employment and the level of UAI in the given country of employment, (Hofstede 2001). Uncertainty avoidance societies inherently avoid risk through stable employer-employee relations. Overall, uncertainty avoidance societies tend to have a longer average duration of employment, presumably due to the job security that is associated with length of tenure.

Uncertainty avoidance can also be linked to employee motivation, especially when analyzing it in conjunction with masculinity. Where uncertainty avoidance is strong, such as Mexico, individuals are most highly motivated by safety and security. Supreme motivators in the United States, where masculinity is relatively high, and uncertainty avoidance is low, are achievement and esteem. Whereas in Mexico, where masculinity is likewise, but uncertainty avoidance is high, the most powerful motivators are security and esteem.

\section{Individualism}

The workplace views individualism in terms of the degree to which an employee acts in their self-interest or the interest of the organization as a whole. In collectivist cultures, the benefit of the employer and the benefit of the employee tend to coincide. Employees act according to the interest of the group rather than indulging self-serving actions, (Hofstede 1991). This trend is especially exemplified in the collectivist tendency to share wages with family. In the workplace, 
Americans tend to place a high value on self-reliance and initiative. Decisions such as hiring, firing, and promotion are generally much more merit related than relationship influenced. Contrarily, in collectivist societies such as Mexico, employer and employee relationships are perceived in relationship terms. For example, employment decisions give high preference to family and those previously employed. While similar trends are known to take place in the United States, they are often perceived negatively due to suspicions of nepotism and fears of conflict of interest, (Hofstede 1991). For example, when employees engage in romantic relations, often on employee needs to transfer departments to avoid conflict of interest issues.

Christopher Earley, an American management researcher, conducted a study in 1989 to illustrate the work methods that people in collectivist and individualist countries thrive in by giving tasks to Chinese and American workers. Certain people needed to perform the entire task as a cohesive group and others required to complete their own delegated portions of the task on their own. Earley found that those who came from a collectivist society, such as China (China scores a 20 on the Individualism Hofstede's Scale), performed best when working anonymously as a group. However, the Chinese participants performed worst when operating individually with their name attached to whatever work was produced. The Americans displayed opposite results, in which the participants created the most quality work when submitting individual, name marked work, and poor outcomes in a team dynamic.

\section{Masculinity}

In this metric, the United States and Mexico rank very similarly on the scale. They land on a 62 and 69, leaning towards being more masculine than feminine but not extremely one 
direction over the other. Masculinity has work implications in terms of which gender most often works, conflict resolution styles and leadership expectations, job enrichment tendencies, and industry success.

A survey among US college students found that young people had significant expectations that men are to aspire to career advancement. When asked about the expectations for women, the results were that some women have career aspirations, but these aspirations are not socially compulsory for women as they are men, (Hofstede, 1980). This societal expectation may have been alleviated somewhat in the past 40 or so years, but still exists today. It should be noted that across almost all industries and societies, female participation in the workforce is increasing. The same study found that feminine oriented societies tend to view the genders more equally in concluding that men or women may have huge career ambitions if they so choose.

Feminine cultures tend to resolve conflicts via compromise and negotiation rather than "fighting it out," (Hofstede, 1991). This distinction leads to differing management styles. Masculinity societies put a higher value "macho" style behaviors such as being assertive, decisive, and aggressive with quick decision-making skills. Contrarily, feminine oriented societies place a higher value on intuition rather than decisiveness by focusing on consensus in the decision-making process. Generally, these attitudes affect how employees go into meetings, whether that be prepared to assert themselves or prepared to discuss solutions collaboratively.

How masculinity index can manifest itself is how Hofstede describes "the humanization of work." In masculine cultures, feeling humanized in a job means to feel "recognition, advancement, and challenge," (Hofstede 1991) to gain a sense of job enrichment. Executing this job enrichment preference could be as simple as allowing production employees to take 
ownership of special tasks such as installment and maintenance of machines rather than only work the line. Expansion of work responsibilities generally makes employees feel "good" about their jobs in a way that is unique to masculine oriented countries. Netherlands, Sweden, and Denmark exemplify feminine cultures and are characterized by craving humanized responsibilities as having opportunities to collaborate and maintain social contracts with others.

Cultural characteristics correlate with industry success in respective countries. Masculine societies, such as China, Germany, and Japan, are world leaders in the manufacturing sector. These countries tend to be characterized as having lean, quick, and efficient operations. Heavy equipment tends to come out of the most masculine societies. Feminine cultures retain a competitive advantage in other sectors such as consulting, transport, and goods according to customer specification. As an example, Japan is a worldwide leader in electronics while Denmark and the Netherlands are known for their services and agricultural exports, (Hofstede, 1991). The degree of masculinity in a society can even heavily influence store operating hours. Denmark and France draw a specific comparison. These two countries rank, overall, femininely scoring 16 and 43 on the scale. These scores indicate that people tend to value "work to live" over "live to work." France has a score of 43 in masculinity making it a pretty feminine country where people treasure "work to live" over "live to work." In France and Denmark, people often leave work early to be able to spend time with their family. An example of this in respect to actual businesses might be the opening hours of shops, closing earlier in Denmark than in France, (Samuel, Clayton, \& Hannah, 2016). 


\section{Customer Perspective}

It is appropriate to consider how culture may influence customer perceptions of service given that the business in question is customer facing and service oriented. A group of researchers in the United Kingdom found significant correlations between societal values and explicit responsiveness to unsatisfactory B2C relations. "The cultural orientation of customers influences their response to customer dissatisfaction. For instance, it appears that customers in high individualistic, low uncertainty avoidance, and low power distance orientation are more likely to express their dissatisfaction by voicing their concerns directly to the service provider," (Klaus, Anders, Nima \& Markus, 2019). This same study concluded that businesses should take higher initiative to obtain feedback from those in low individualistic, high uncertainty avoidance and high power distance countries than the effort that would be ordinarily needed when working with customers who have a greater tendency to speak their minds with business owners.

\section{Compensation and Benefits Practices}

Cultural orientations have effects on best practices for employee compensation in addition to organizational behavior. Employee compensation is important to study because of all the human resources management functions, compensation is a fundamental one that significantly impacts the organization and employees within, (Bonache \& Fernandez, 1997). As certain assets become more and more common, such as financial capital and technology, firms are increasingly relying on human assets to sustain a competitive advantage (Barney, 1991). This is especially true of small businesses with little resources compared to that of an entire corporation. A study aimed to examine the possible relationships between cultural values and 
preferred reward policies and found that culture while can often be held responsible for affecting monetary incentives, the effects should overall be considered partial and moderate because only specific cultural orientations are likely to relate to pay policies, (Yeganeh \& Su, 2011).

Of course, legislative and employment rate contexts heavily influence compensation worldwide. However, national culture measured by Hofstede's Dimensions has been found to have an impact on compensation. Research by two scholars found that there are correlations between compensation practice and national culture without controlling for certain independent factors such as industry or company size. They found that there is a statistically significant relation between seniority-based and skill-based compensation systems in relation to uncertainty avoidance index. In addition, high masculinity seems to be associated with less use of flexible benefits, work-place child-care programs, career-break schemes, and maternity-leave programs. Last, it was found that individualism is a strong driver of pay-for-performance compensation plans, (Schuler \& Rogovsky 1998).

\section{Case Study}

In this case study, a group of researchers studied a Thai small to medium-sized manufacturing organization of 50 employees and aimed to develop a basic understanding of the innovation process in Thailand given five Hofstede Cultural Dimensions that relate to the innovation concept, (Rujirawanich, Addison, \& Smallman 2011). Thailand scores similarly to Mexico in a few dimensions, particularly in its intermediate score on Uncertainty Avoidance, indicating that the society is risk averse. This organization won several product quality awards and was highly respected in Bangkok. Researchers interviewed a variety of employees from all 
levels including managers, sales people, accountants, shop floor employees, etc. All participants were interviewed, in native Thai language, about the innovation process on a variety of products in several departments.

Overall, the researchers findings are such that Thai small to medium-sized organizations more effectively adopt incremental change rather than radical change and most of the interviewees displayed classic characteristics of how Hofstede's Dimensions notably relate to the work context. The researchers also synthesized with surety that individualism appears to be important at least in the initiating and concluding phases of innovation and high power distance and uncertainty avoidance levels are innovation inhibitors. These findings are in line with the researchers' initial hypothesis. This is due to the conclusion that four of the five dimensions analyzed disrupt the innovation process. The study also sought to consider if there are additional cultural factors that influence innovation in addition to Hofstede's Dimensions which resulted in a conclusion that traditional culture in Thailand is shifting as more and more people gain access to and consume Western media, and therefore attitudes may change in coming years. The research implications for these findings underly the need to understand the local environment in trends in addition to uses a macro societal lens when considering success or failure of innovation activity, especially when the organization is small to medium-sized.

\section{Thesis Paper Limitations and Directions for Future Research}

This review is not without limitations. First, a major limitation of this review is the focus on research from Geert Hofstede. While additional peer-reviewed sources are both cited and considered, the recommendations are largely based on this researcher's work. Though Hofstede 
is widely regarded as the best framework for understanding culture, largely depending on one primary body of research results in a somewhat narrow lens. Second, the majority of the research on cultural implications in the workplace focus on large business entities, such as corporations, and do not consider small business enterprises. Therefore, many assumptions must be made when translating case study results from large businesses to a smaller scale. Third, when discussing cultural matters, most research is qualitative, which while useful in understanding the nuances in an employee's experience, do not allow for statistical analysis.

As such, I recommend that future research be oriented towards measurement in conjunction with experience, to enable a more comprehensive analysis of cultural dimensionality. Future research on societal trends effectively translating into the workplace could result in positive and cost-savings effects for business small and large alike through decreased turnover and higher employee engagement and motivation, which leads to better productivity outcomes. In addition, the Human Resources field would benefit from this research in a variety of job fields and industries, to determine what, if any, particular job roles are more impacted by societal culture in the workplace compared to others. Studying diverse work environments will allow a richer, more broad-ranging understanding of how to attract, motivate, and engage employees given the location of operation.

\section{Recommendations}

A large proportion of firms acknowledge the importance of cross-cultural differences and the existence of national culture-specific policies and practices, but do not know how to address the relationship between facets of national culture and specific HR practices (Hendry, 1992). 
Many organizations realize the value in being adaptable to respective cultures when conducting business, and the findings of this literature review uphold the notion that organizations must consider respective countries of operation when conducting business. This is especially pertinent in a small business setting, as this is what may provide a small business a key competitive advantage compared to large corporation counterparts. Often, employees working in small businesses expect the employee-employer relationship to be more personal and in touch with the culture of the surrounding area than employees working for a large corporation. This may be attributed to the fact that many large corporations, and the retail stores, specifically in those corporations, must live up to a non-negotiable expectation of store homogeneity. Meaning, one big box clothing store, such as a Macy's in New York, for example, should look and operate very similarly to a Macy's in California. While striving for similarity can be good in that it drives a consistent customer experience across all stores, it also opens a unique opportunity for small businesses. Eliminating bottlenecks and bureaucracy of larger businesses enables small businesses to quickly respond to dynamic customer needs.

The first recommendation is to consider the organizational structure of a retail space in either the United States or Mexico given power distance levels of each country. Because the United States is a low power distance society, a flat organizational structure may suit the business best. A flat organizational structure refers to a business structure with few to no levels of management between leaders and staff level employees. This structure allows for more responsibility and little supervision. It also encourages a quicker decision-making process as the speed of communication between employees increases. Besides, reducing middle management salaries lowers payroll costs. The disadvantage to a flat structure may include confusion among 
employees as to which boss to report to and power struggles without a clearly defined leader. Also, flat structures may produce adept generalists but little specialists, meaning when job functions may be blurry due to flat structures, employees become a jack of all trades but master of none. Flat structures can often suit small businesses best because small businesses tend to be more intimate and informal rather than formal. Having a limited amount of employees suits flat structures well. Also, it is unknown if Company $\mathrm{X}$ will have the necessary resources to justify middle management expenditure. One thing to note is that as organizations grow from small business, the harder it becomes to maintain an effective flat structure. Contrarily, assuming the store is located in Mexico, I recommend a vertical structure of hierarchy in the store. The stiff power distance that characterizes this society favors strong leaders at the top and clearly designated tasks to each employee. Of course, neither recommendation advises to maintain stringent and rigid structures, but rather blend the two with a focus on one or the other given local attitudes towards authority.

The second recommendation is to align total compensation and benefits practices with societal values. In regards to compensation, scholars usually refer to it as monetary and non-monetary payment for employment, which can include base salary, bonuses, programs, or even intangible benefits. Tessema and Embaye found that in countries having more progressive policies, such as the United States, benefits play a larger role on employee satisfaction in a total compensation package than they do in more traditional countries, where employees put more on straight monetary pay, (2013). Mexico and the United States differ in terms of their uncertainty avoidance index, with Mexico high at 82 and the United States reasonably low at 46 . That being said, pay structures should vary in a store by pay-for-seniority and pay-by-performance. An 
example of pay-for-seniority in a retail store would be rewarding employee tenure with an annual increase that proportionally reflects higher percentages given the length of service. Alternatively, in the United States, an individualist society with uncertainty tolerance, a better program would be pay-for-performance. In this compensation program, a retail employee may receive, for example, $10 \%$ commission for each piece sold, in addition to base wage. Due to the strongly individualistic nature of the United States, pay-for-performance should be based on individual results, rather than organizational results, given the country's overwhelming preference for individual orientation than group accomplishment. These compensation practices, in conjunction, will effectively meet employees' societal mindsets and inclinations.

In conclusion, while research mainly emphasizes business practices for large companies, there are many adaptations that small businesses can sensibly implement to accommodate and engage employees in consideration of local customs and predispositions. 


\section{References}

Barney, Jay. 1991. Firm resources and sustained competitive advantage. Journal of Management, 17: 99-120.

Bonache, J. and Fernandez, Z. 1997. Expatriate Compensation and its Link to the Subsidiary Strategic Role: A Theoretical Analysis. International Journal of Human Resource Management, 8: 457-475.

Earley, P. C. (1989). Social Loafing and Collectivism: A Comparison of the United States and the Peoples Republic of China. Administrative Science Quarterly, 34(4), 565. doi: $10.2307 / 2393567$

Green, E. (2016, May 16). What are the most-cited publications in the social sciences (according to Google Scholar)? Retrieved from https://blogs.lse.ac.uk/impactofsocialsciences/2016/05/12/what-are-the-most-citedpublications-in-the-social-sciences-according-to-google-scholar/

Hempel, P. S. (1998). Designing multinational benefits programs: The role of National culture. Journal of World Business, 33(3), 277-294. doi:10.1016/s1090-9516(99)80075-3

Hodgetts, R. (1993). A conversation with Geert Hofstede. Organizational Dynamics, 21(4), 53-61. doi:10.1016/0090-2616(93)90033-w

Hofstede, G. (2011). Dimensionalizing Cultures: The Hofstede Model in Context. Online Readings in Psychology and Culture, 2(1). doi:10.9707/2307-0919.1014

Lowe, K. B., Milliman, J., Cieri, H. D., \& Dowling, P. J. (2002). International 
Compensation Practices: A Ten-Country Comparative Analysis. Asia Pacific

Journal of Human Resources, 40(1), 55-80. doi:10.1177/1038411102401005

Maertz, C. P., Griffeth, R., \& Hom, P. (Eds.) (2004). Innovative theory and empirical research in employee turnover. Greenwich, CT: Information Age.

McGraw, P. (2015). Changing patterns of compensation and benefits in multinational and Australian companies 1996-2009. Asia Pacific Journal of Human Resources, 53(1), 59-82. https://doi-org.proxy.lib.pdx.edu/10.1111/1744-7941.12040

Meyer, J. P., \& Stanley, D. J. (2002). Affective, Continuance, and Normative Commitment to the Organization: A Meta-analysis of Antecedents, Correlates, and Consequences. Journal of Vocational Behavior, 61(1)

More Multinationals Embracing Centralized Compensation Structures. (2006). Business Credit, 108(9), 58. Retrieved from http://stats.lib.pdx.edu/proxy.php?url=http://search.ebscohost.com.proxy.lib.pdx.ed $\underline{\mathrm{u} / \operatorname{login} . a s p x ? \text { direct }=\text { true } \& \mathrm{db}=\text { buh } \& \mathrm{AN}=22836630 \& \text { site }=\text { ehost-live }}$

National Culture. (n.d.). Retrieved from https://www.hofstede-insights.com/models/national-culture/

Newman, Karen L. \& Stanley D. Nollen. 1996. Culture and congruence: The fit between management practices and national culture. Journal of International Business Studies, 27(4): 753-78

Punnett, Betty J. \& D. A. Ricks. 1992. International business. Boston: PWS- Kent.

Ramesh, A., \& Gelfand, M. J. (2010). Will they stay or will they go? The role of job embeddedness in predicting turnover in individualistic and collectivistic cultures. 
Journal of Applied Psychology, 95(5), 807-823. doi:10.1037/a0019464

Rothausen, T. J., Gonzalez, J. A., \& Griffin, A. E. (2008). Are all the parts there everywhere? Facet job satisfaction in the United States and the Philippines. Asia Pacific Journal of Management,26(4), 681-700. doi:10.1007/s10490-008-9116-1

Rujirawanich, P., Addison, R., \& Smallman, C. (2011). The effects of cultural factors on innovation in a Thai SME. Management Research Review, 34(12), 1264-1279. doi:10.1108/01409171111186397

Schoefer, K., Wäppling, A., Heirati, N., \& Blut, M. (2019, 05). The moderating effect of cultural value orientations on behavioral responses to dissatisfactory service experiences. Journal of Retailing and Consumer Services, 48, 247-256. doi:10.1016/j.jretconser.2019.02.009

Schuler, R. S., \& Rogovsky, N. (1998). Understanding Compensation Practice Variations Across Firms: The Impact of National Culture. Journal of International Business Studies, 29(1), 159-177. doi:10.1057/palgrave.jibs.8490030

Sekiguchi, T. (2004). The role of different types of person-organization fit in Japanese recruiters' judgments of applicant qualifications: An experimental policy-capturing investigation. Japanese Association of Industrial/Organizational Psychology Journal, 17, 51- 63 .

Sinha, J. B. P., \& Sinha, D. (1990). Role of social values in Indian organizations. International Journal of Psychology, 25, 705-714.

Small Business Administration. (n.d.). Retrieved from https://www.sba.gov/

Tessema, M., Ready, K., \& Embaye, A. (2013). The Effects of Employee Recognition, Pay and Benefits on Job Satisfaction: Cross Country Evidence. Journal of Business and 
Economics, 4 (1), 1-13.. Journal of Business and Economics. 4. 1-13.

Yeganeh, H., \& Su, Z. (2011). The effects of cultural orientations on preferred compensation policies. The International Journal of Human Resource Management, 22(12), 2609-2628. doi:10.1080/09585192.2011.588036 